DOi: $10.21554 /$ hrr.042002

\title{
CHARACTERISTICS OF ADULT PEOPLE WITH FLUENCY DISORDER
}

Original scientific paper

\section{Isidora Radonjić a}

\section{Nada Dobrota Davidovića (Ret.)}

\section{Danka Radulovića}

Jadranka Otaševića

Darinka Šoster ${ }^{b}$

\section{Dragomir Davidovićc}

${ }^{a}$ Faculty of Special Education and Rehabilitation, University of Belgrade, Republic of Serbia

${ }^{b}$ Institute of Psychophysiological Disorders and Speech Pathology "Prof. Dr. Cvetko Brajović", Belgrade, Republic of Serbia

'Clinic for psychiatric diseases "Dr Laza Lazarević”, Belgrade, Republic of Serbia

Received: $2 / 19 / 2020$

Accepted: $3 / 29 / 2020$

\begin{abstract}
The aim of this study is to test the thesis that adults who stutter differ from those without this disorder by lower birth weight and in terms of personality dimensions, as well as the assertion that prevalence of stuttering is far higher among males.Total sample consisted of 108 subjects, aged 18 - 50, whereby subsamples consisted of 54 subjects, equaled in gender and age. The Personality Inventory NEO PI_R (S/A form) was used to examine basic personality dimensions (Neuroticism, Extraversion, Openness, Agreeableness and Conscientiousness). The correlation between the gender and stuttering has been established, but no differences have been found between the birth weights or in terms of basic personality characteristics. Further examinations are needed but such should be applied to larger representative samples, using more progressive data processing methodology.
\end{abstract}

Key words: fluency disorders, stuttering, personality dimensions, gender, birth weight

\footnotetext{
${ }^{1}$ Correspondence to:

Jadranka Otašević, Faculty of Special Education and Rehabilitation, University of Belgrade, Republic of Serbia Visokog Stevana 2, Belgrade, Republic of Serbia

Phone: +381693550337

E-mail: jadrankastevovic@yahoo.com
} 


\section{INTRODUCTION}

Most commonly, when thinking about fluency, one usually means fluid, effortless speech without any interruptions, repetitions or prolongations of syllables. On the other hand, speech disfluency involves incorrect pronunciation; with speech rhythm and tempo are excessively disturbed as some of the basic suprasegmental speech structures. Fluency disorder is a pathological state that can appear both among children and adults. Pathological states having fluency disorder as their syndrome include: tachyphemia or rapid speech syndrome, palilalia, apraxia, parkinsonism, spasmodic dysphonia, Tourett's syndrome, neurogenic stuttering, but also stuttering manifested in disorders of all fluency forms with prominent changes in somatic, psychological and social sphere, which are all subjects of the present study. The most prominent stuttering symptom is a complicated and interrupted verbal communication with disturbed feedback. When it comes to the prevalence, stuttering is the second speech- language disorder, present among all ages, but most frequently between the age of 2 and 3, and between 4 and 5 years of age (Dobrota, Otašević, \& Radević, 2018).

Epidemiological data reveal that correlation between the gender and speech pathology is important for understanding this matter, since speech-language disorders are substantially more prevalent among men than women. Yairi and Ambrose find this proportion to be 3:1 (Yairi \& Ambrose, 2013).

Researches indicate that birth weight is one of the risk factors for untypical neurological (Walhovd at al., 2012) and psychosocial development (Rygaard, 1998 according to Radulović, 2006). Boulet and associates (Boulet, Schieve, \& Boyle, 2011) established correlation between birth weight and stuttering, but the empirical data concerning this subject are still inconsistent (McAllister \& Collier, 2014).

The etiology of disfluent speech has been in focus of numerous scientists for many years now. The relevant etiological factors comprise genetic predispositions, neurologic deficits and psychological factors, either individually or as combination thereof.
During the first half of the $20^{\text {th }}$ century, the most common opinion was that stuttering was related to various forms of pathology, presence of neuroticism and unconscious personality conflicts (Bloodstein \& Bernstein-Ratner, 2008). More recent studies give greater significance to a combination of genetic and neurophysiological factors influencing the speech and language production, potentially resulting in stuttering (Cykowski, Fox, Ingham, Ingham, \& Robin, 2010). However, even in this constellation an important aspect of stuttering is the psychological one, so that people with this disorder quite commonly tend to be anxious, quailed, socially isolated, withdrawn, depressed, pessimistic, fearful, prone to phobias especially to logophobia (Tran, Blumgart, \& Craig, 2011). The aggravating factors in treatment of stuttering disorder can include the temper and certain personality traits of a treated person, which build up to and contribute to a negative self-assessment, as well as noticeable psychopathological personality tendencies (Radoman, 2004). The present study therefore addresses, in addition to gender and birth weight, certain basic personality dimensions of adults who stutter and of persons from typical population.

\section{Subject and objective of the study}

The subject of the present study is to establish:

a) gender differences with regard to the prevalence of stuttering;

b) differences in birth weight between adults who stutter and those from typical population; c) differences in personality dimensions between adults who stutter and those without this disorder; and d) differences in personality structure between men and women undergoing the speech treatment for their stuttering.

The objective of this study is to verify the not always consistent findings from foreign literature, referred to in the Introduction, about the existence of differences in the stated characteristics between the experimental and control groups, taking into account their significance for the prediction of treatment outcome. 


\section{METHODOLOGY}

\section{Sample}

Total sample included 108 respondents between 18 and 50 years of age (Table 1 ).

Table 1. Sample distribution by age

\begin{tabular}{cccccc}
\hline Group & N & Min & Max & M & SD \\
\hline Experimental & 54 & 18 & 47 & 26.69 & 6.89 \\
Control & 54 & 18 & 50 & 26.67 & 6.91 \\
Total & 108 & & & &
\end{tabular}

The subsamples consisted of 54 respondents in the experimental and the same in the control group, equalized in age and gender (Table 1 and Table 2).

Table 2. Sample distribution by gender

\begin{tabular}{ccc}
\hline Group/gender & Frequency & Percentage \\
\hline Experimental & & \\
Male & 38 & 70.4 \\
Female & 16 & 29.6 \\
Total & 54 & 100.0 \\
\hline Control group & & \\
Male & 38 & 70.4 \\
Female & 16 & 29.6 \\
Total & 54 & 100.0 \\
\hline
\end{tabular}

The experimental group of respondents (38 men and 16 women) comprised all adult patients from the Institute for Psychophysiological Disorders and Speech Pathology "Prof. Dr Cvetko Brajović" from Belgrade, who were involved in regular logopedic therapy for fluency disorder in the course of two months, while data gathering for this study took place. The treatment applies complex, comprehensive and empirically verified study developed by Professor Cvetko Brajović, called "Conscious Synthesis of Development (CSD)". This methodology is regarded as the most efficient and most appropriate one in stuttering treatments (Dobrota, Otašević, \& Radević, 2018). The control group of 54 adult respondents from typical population, aged between 18 and 50, who had never expressed any symptoms of stuttering, comprised students offinal grades in Mathematical Grammar School, students of final semesters and graduate students of the
University in Belgrade (Faculty of Special Education and Rehabilitation, Faculty of Sport and Physical Education and Faculty of Music), as well as members of scouting and mountaineering organizations.

\section{Variables and Instruments}

The research included variables treated in recentempirical literature as important risk factors when it comes to stuttering: gender, low birth weight and basic personality dimensions. Low birth weight can be an indication for neuropsychological correlates of developmental disorders, including speech pathology; as a reference for low birth weight, a value of less than $2500 \mathrm{~g}$ is assumed, determined as per McAllister and Collier (McAllister \& Collier, 2014). Data concerning gender and birth weight became available as self-reported by the respondents in a form of anonymous general questionnaire composed of nine questions, including sociodemographic data about the respondents. Personality variables were taken from the 'Big-Five' model (Digman, 1990), which assumes a hierarchical personality structure defined through the five basic domains, i.e. personality dimensions: Neuroticism, Extraversion, Openness, Agreeableness and Conscientiousness, forming the basis of personality traits. The 'Big-Five' model is based on the factor analysis of lingual phrases in different cultures. The basis of this model is the notion that individual differences are in essence the differences in the intensity of basic personality dimensions, and that such intensity differentiates between pathological and normal. Personality variables defined in such a way were measured through a shortened version of the verified Personal Inventory NEO PI_R (NEO-FFI) whose authors are Costa and McCrae (Costa \& McCrae,1992) and whose Serbian adaptation (S/A form) was done by Knežević, Đurić-Jočić and Džamonja-Ignjatović (2009). Each dimension is covered in the test with 12 items that examine the underlying personality traits i.e. facets within each dimension. The test contains a total of 60 items formulated as assertions (in Likert's scale format) within a range between 1 and 5 responded by the respondents of the experimental and control groups in the form of a self-report. 
The instrument has good metric characteristics, which can be observed from the reliability coefficients of tests (scales) used for the purpose of measuring the main personality dimensions (Table 3 ).

Table 3. Reliability coefficients of the applied Personality Inventory

\begin{tabular}{ccc}
\hline Test scales & $\begin{array}{c}\text { Reliability } \\
\text { coefficient }\end{array}$ & $\begin{array}{c}\text { Reliability } \\
\text { type }\end{array}$ \\
\hline 1. Neuroticism & .75 & Cronbach \\
2. Extraversion & .73 & Cronbach \\
3. Openness & .71 & Cronbach \\
4. Conscientiousness & .69 & Cronbach \\
5. Agreeableness & .69 & Cronbach \\
\hline
\end{tabular}

Knežević, Radović and Opačić (1997) also find that the representativeness of the NEO PI_R items for each scale remains high, that the scales are reliable and that the homogeneity coefficients are relatively low, so that for this measuring instrument both the factor and the taxonomy validity is confirmed. The Personal Inventory was appraised as very good and of a high quality by the same authors who recommended it for all occasions wherein a reliable assessment of respondent personality structure is needed. However, they deem that one quarter of mainly negatively formulated items should be transformed, since they require unnecessary cognitive efforts of the respondents in solving the double-negation problem (Knežević and associates, 1997). We reassured ourselves of these statements while gathering field data, especially for the experimental group, because some respondents asked for help in interpretation of assertions with double negations.

Nevertheless, NEO PI_R is one of the best Personality Inventories, also in the opinion of some other authors, measuring individual differences in personality dimensions of healthy people, but also of those with psychopathological tendencies in a form of a self-report (Bleek, Reuter, Yaruss, Cook, Faber \& Montag, 2012). Taking that into account, as well as the fact that the instrument is based on the analysis of expressions used in everyday speech and that it is applied in the research of personal correlates of stuttering by other authors, thus enabling comparison of findings, the Inventory has also been selected for personality assessment in the present study.

\section{Research procedure}

Examination of the experimental group was conducted in March and April 2017 on the premised of the Institute. Following the approval of the Institute Ethics Committee, data gathering and the examination of the experimental group started. Each respondent from the experimental group personally signed the Consent to take part in the research. This Consent contained information about the research objective and statements that the research was anonymous, as well as that the personal data would be used only for scientific purposes and would be protected from any abuse in accordance with the Law on Personal Data Protection (Official Gazette of RS, no. 97/2008, 104/2009 - state law, 68/2012 CC decision and 107/2012 2 ). The signed Consent is attached to the medical record of every member from the experimental group.

The control group members were examined in April 2017.

\section{Data Processing}

The collected data were processed applying methodologies of descriptive and inferential statistics: chi-square test, ttest, Shapiro-Wilk test and U-test.

Negatively reflected items in the NEO PI_R(S/A form) instrument had been previously recoded applying the "key" and the summary scores on the scales and subscales were derived. The instrument discrimination was examined through Shapiro-Wilk test. The instrument subscales, scores of which significantly deviated from the normal distribution model, were examined through Mann-Whitney test (U-test). For the purpose of checking the internal test reliability, the Cronbach-alpha internal reliability coefficient was used with $\alpha=.70$ as the limit. All collected data were processed using software package SPSS, version 23.

2 Official Gazette of RS, no. 97/2008, 104/2009 - state law, 68/2012 - CC decision and 107/2012 


\section{RESULTS}

The research has revealed statistically significant difference in the frequency of male population with speech fluency disorder compared to that of female population with the same diagnosis (Table 4).

Table 4. Subsamples distribution by gender

\begin{tabular}{|c|c|c|c|c|}
\hline \multirow{5}{*}{$\begin{array}{l}\overrightarrow{\bar{v}} \\
\overrightarrow{0} \\
\overline{0}\end{array}$} & & $\begin{array}{l}\text { Experimental } \\
\text { group }\end{array}$ & $\begin{array}{l}\text { Control } \\
\text { group }\end{array}$ & Total \\
\hline & & $\mathbf{N}$ & $\mathbf{N}$ & $\Sigma$ \\
\hline & Male & 38 & 38 & 76 \\
\hline & Female & 16 & 16 & 32 \\
\hline & Total & 54 & 54 & 108 \\
\hline
\end{tabular}

The results of applying the univariate chi-square test have demonstrated that the observed difference in the frequencies concerning gender as variable category is statistically significant in the experimental group of respondents $\left(\chi^{2}=8.96 \mathrm{df}=1, p \leq .01\right)$.

Discrepancy in birth weight between the subjects from experimental and control groups (Table 5) was tested applying $\mathrm{t}$ - test for independent samples.

Table 5. Arithmetic means and standard deviations on birth weight variable in experimental and control groups

\begin{tabular}{lcccc}
\hline Birthweight & N & M & SD & SEM \\
\hline Experimental & 54 & 3321.22 & 786.76 & 107.06 \\
Control & 54 & 3352.56 & 770.44 & 104.84 \\
\hline
\end{tabular}

This test has demonstrated that no statistically significant differences exist in the birth weight between the respondents from the experimental and control groups at the entire sample level: $(t=-$ $.21, \mathrm{df}=106, p=.84)$. The average birth weight for the experimental group respondents was $3321.22 \mathrm{~g}$, which substantially exceeds the limit of $2500 \mathrm{~g}$. The results of the study indicate there are no statistically significant differences in the personality structure between the experimental and control groups (Table
6), nor is there difference in personality dimensions between men and women from the experimental group (Table 7).

Table 6. Arithmetic means and standard deviations on personality variables in experimental and control groups

\begin{tabular}{lcccccc}
\hline & \multicolumn{7}{c}{ Group } \\
\hline & Exp. & Con. & Exp. & Con. & Exp. & Con. \\
\hline Personality traits & N & N & M & M & SD & SD \\
\hline Neuroticism & 54 & 54 & 2.87 & 2.72 & .71 & .54 \\
Extraversion & 54 & 54 & 3.24 & 3.28 & .53 & .47 \\
Openness & 54 & 54 & 3.33 & 3.32 & .45 & .51 \\
Agreeableness & 54 & 54 & 3.46 & 3.37 & .50 & .51 \\
Conscientiousness & 54 & 54 & 3.82 & 3.78 & .53 & .59 \\
\hline
\end{tabular}

The results of t-test applied to independent samples demonstrated no significant differences in personality dimensions (on each subscale) between the experimental and control groups: Neuroticism $(t=1.25, \mathrm{df}=106$, $p=.22$ ), Extraversion ( $t=-.48, \mathrm{df}=106, p=.63)$, Openness $(t=.06, \mathrm{df}=106, p=.95)$, Agreeableness $(t=.89, \mathrm{df}=106$, $p=.38)$, Conscientiousness $(t=.37, \mathrm{df}=106, p=.71)$.

Table 7. Arithmetic means and standard deviations on personality variables of men and women within experimental group

\begin{tabular}{lllccc}
\hline Group & Gender & Personality Traits & N & M & SD \\
\hline Experimental & \multirow{2}{*}{ Men } & Neuroticism & 38 & 2.77 & .62 \\
& & Extraversion & 38 & 3.30 & .50 \\
& & Openness & 38 & 3.31 & .39 \\
& Agreeableness & 38 & 3.40 & .49 \\
& Conscientiousness & 38 & 3.86 & .51 \\
\cline { 3 - 6 } & \multirow{2}{*}{ Women } & Neuroticism & 16 & 3.09 & .88 \\
& & Extraversion & 16 & 3.10 & .61 \\
& Openness & 16 & 3.38 & .59 \\
& Agreeableness & 16 & 3.60 & .49 \\
& Conscientiousness & 16 & 3.73 & .58 \\
\hline
\end{tabular}

The results of t-test applied to independent samples between men and women in terms of personality dimensions in the experimental group demonstrate no statistically significant differences at any subscale: 
Neuroticism $(t=-1.52, \mathrm{df}=52, p=.13)$, Extraversion $(t=1.26, \mathrm{df}=52, p=.21)$, Openness $(t=-.50, \mathrm{df}=52$, $p=.62)$, Agreeableness $(t=-1.37, \mathrm{df}=52, p=.18)$ and Conscientiousness $(t=.80, \mathrm{df}=52, p=.43)$.

The instrument discrimination was tested by the Shapiro-Wilk test of scores distribution normality (Table 8).

Table 8. Results of Shapiro-Wilk test application of distribution normality on scores in personality variables for total sample

\begin{tabular}{lccc}
\hline & \multicolumn{3}{c}{ Shapiro-Wilk test } \\
\hline & W & Df & $\boldsymbol{P}$ \\
\hline Neuroticism & .98 & 108 & .09 \\
Extraversion & .98 & 108 & .14 \\
Openness & .96 & 108 & .00 \\
Agreeableness & .93 & 108 & .00 \\
Conscientiousness & .97 & 108 & .03 \\
\hline
\end{tabular}

The results of the Shapiro-Wilk test demonstrate statistically significant deviation in the empirical scores distribution on the Openness subscales ( $W=.96, p \leq 01)$, Agreeableness $(W=.93, p \leq .01)$ and Conscientiousness $(W=.97, p=.03)$, whereas the scores on the other subscales of personality variables, including neuroticism, are normally distributed.

The statistical significance of the horizontal and vertical deviations has also been examined (Table 9).

Table 9. Arithmetic means, standard deviations and dispersion measures for the distributions of results in personality variables for total sample

\begin{tabular}{lccccccc}
\hline & N & M & SD & \multicolumn{2}{c}{ Skewness } & \multicolumn{2}{c}{ Kurtosis } \\
& & & & Stat. & SEsk & Stat. & SEku \\
\hline Neuroticism & 108 & 2.79 & .64 & .40 & .23 & .55 & .46 \\
Extraversion & 108 & 3.26 & .50 & -.32 & .23 & -.22 & .46 \\
Openness & 108 & 3.32 & .48 & -.71 & .23 & .23 & .46 \\
Agreeableness & 108 & 3.41 & .50 & -.92 & .23 & 4.65 & .46 \\
Conscientiousness & 108 & 3.80 & .56 & -.34 & .23 & -.02 & .46 \\
\hline
\end{tabular}

The statistical significance test for the horizontal deviation on the Openness subscale (Figure 1) indicates that standardized skewness equals to -3.09 (skewness $=-.71$ and $\mathrm{SEsk}=.23$ ) and $p \leq .01$, whereas the statistical significance test for the vertical deviation on the same subscale demonstrates that standardized kurtosis equals to .5 (kurtosis $=.23, \mathrm{SEKu}=.46$ ) and $p \geq .05$ (negatively asymmetric distribution).

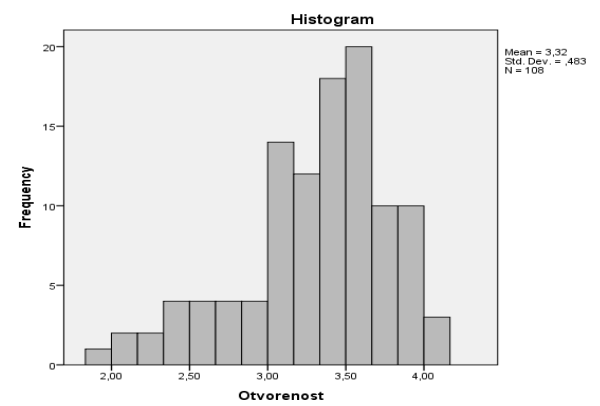

Figure 1. Scores distribution on the Openness subscale

The statistical significance test for the horizontal deviation on the Agreeableness subscale (Figure 2) demonstrates that the standardized skewness equals to -4 (skewness $=-.92$ and SEsk $=.23$ ) and $p \leq .01$, whereas the statistical significance test for vertical deviation on the same subscale indicates that the standardized kurtosis equals to 10.11 (kurtosis=4.65, SEku=.46) and $p \leq .01$ (negatively asymmetric distribution leptokurtic curve).

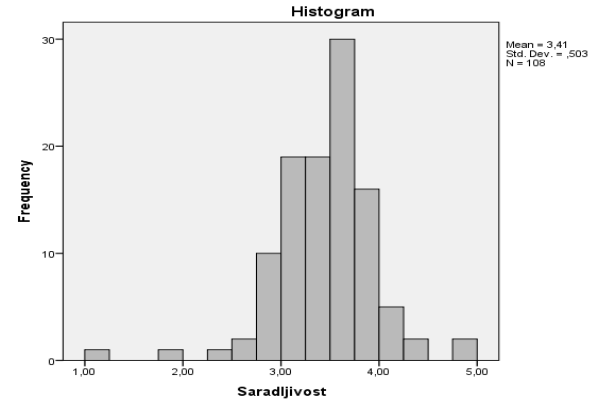

Figure 2. Scores distribution on the Agreeableness subscale

The statistical significance test for the horizontal deviation on the Conscientiousness subscale (Figure 3) indicates that the standardized skewness equals to -1.48 (skewness $=-.34$ and $\mathrm{SEsk}=.23$ ) and $p \geq .05$, whereas the statistical significance test for the vertical deviation on the same subscale demonstrates that the standardized kurtosis equals to -.04 (kurtosis=-.18, $\mathrm{SEku}=.46$ ) and $p \geq .05$ (negatively asymmetric distribution - platykurtic curve). 


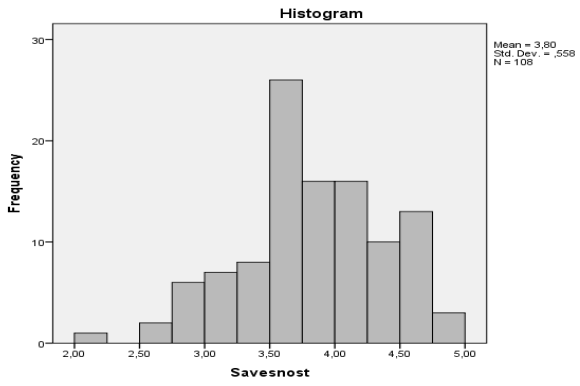

Figure 3. Scores distribution on the Conscientiousness subscale

Since it has been established that the empirical scores distribution concerning personality dimensions indicates significant statistical deviation from the normal one on Openness, Agreeableness and Conscientiousness subscales, the collected data have also been processed applying the non-parametric Mann-Whitney test (Table 10).

Table 10. Medians of experimental and control groups on personality variables (measured by Man-Whitney test)

\begin{tabular}{lllllll}
\hline $\begin{array}{l}\text { Person a lity } \\
\text { dimensions }\end{array}$ & Exp. & Contr. & Exp. & Contr. & Exp. & Contr. \\
\hline & N & N & Mdn & Mdn & IQR & IQR \\
\hline Neuroticism & 54 & 54 & 2.91 & 2.75 & 0.77 & 0.77 \\
Extraversion & 54 & 54 & 3.25 & 3.33 & 0.81 & 0.67 \\
Openness & 54 & 54 & 3.42 & 3.42 & 0.58 & 0.69 \\
Agreeableness & 54 & 54 & 3.50 & 3.42 & 0.58 & 0.58 \\
Conscientiousness & 54 & 54 & 3.75 & 3.75 & 0.71 & 0.65 \\
\hline
\end{tabular}

The results of the non-parametric Mann-Whitney test (U-test), by the means of which differences in medians are examined, also demonstrate no statistically significant differences in the personality dimensions between the experimental and control groups: Neuroticism $(U=1300.50$, $p=.33)$, Extraversion $(U=1373.00, p=.60)$, Openness $(U=1425.50, p=.84)$, Agreeableness $(U=1326.00, p=.42)$ and Conscientiousness $(U=1436.00, p=.89)$.

Reliability of the applied NEO PI_R (S/A form) instrument on the examined sample was tested through Cronbach $\alpha$ index (Table 11).
Table 11. Reliability coefficients for personality subscales of total sample (measured by Cronbach $\alpha$ index)

\begin{tabular}{llc}
\hline \multicolumn{1}{c}{ Subscale } & $\begin{array}{c}\text { Reliability } \\
\text { coeff. } \\
(\boldsymbol{\alpha} \text { index }\end{array}$ & $\begin{array}{c}\text { (number of items } \\
\text { in scales) }\end{array}$ \\
\hline Neuroticism & .79 & 12 \\
Extraversion & .68 & 12 \\
Openness & .53 & 12 \\
Agreeableness & .64 & 12 \\
Conscientiousness & .80 & 12 \\
\hline
\end{tabular}

Application of the internal consistency test to each particular item on Neuroticism $(\alpha=.79)$ and Conscientiousness subscales $(\alpha=80)$ indicate high items interrelations in these subscales, as well as high internal consistency (reliability). The internal items reliability on Extraversion subscale for $\alpha$ index attains sufficiently high limits $(\alpha=.68)$, while internal consistency of Agreeableness items indicates somewhat lower values $(\alpha=.64)$, whereas values significantly lower than the limiting ones are found for Openness subscale $(\alpha=.53)$.

\section{DISCUSSION}

Applying the basic, descriptive level of analysis and by checking the earlier findings on the correlation between the gender and stuttering, this study sought to verify the inconsistent empirical argumentation of foreign authors who found substantial differences between the adults who stutter and those from typical population without this disorder.

The results of this research regarding the correlation between the gender and stuttering are in accordance with the earlier studies which have confirmed that stuttering men are two to three times more numerous than women with the same diagnosis (Reilly et al., 2009). According to Yairi and Ambrose, the proportion is $3: 1$, but the younger the respondents, the lower the proportion (Yairi \& Ambrose, 2013). Nevertheless, boys are at significantly higher risk of developing chronic stuttering than girls. The study of Watkins and associates (Watkins, Yairi \& Ambrose, 1999) reveals an increasing number of male respondents who stutter in adolescence compared to their early childhood, as well as a higher percentage of spontaneously cured stuttering disorders among women. 
It is assumed that statistically significant difference in prevalence of stuttering between the two genders is due to genetic factors, most probably to the influence of brain structures that are connected to speechlanguage processes (Ambrose, Cox, \& Yairi, 1997). For instance, in families where there is a stuttering child, it is more commonly the father that stutters than the mother, and brothers more commonly than sisters. These statements are corroborated by the results of Cox and associates (Cox et al., 2005).

The existence of statistically significant differences in the frequencies between men and women from the experimental group in this research, most likely reflects the real picture of gender structure in the category of stuttering persons; but it is quite likely that spontaneous curing of stuttering among women occurred to certain percentage in their earlier age, so that fewer females request logopedic therapy. This must be studied in more detail and as subject of another study.

The difference in birth weight between the experimental and control groups was examined starting from Packman's standpoint that the fundamental cause of stuttering is a neurological deficit (Packman, 2012) and that birth weight is an important risk factor for irregular neurological development (Walhovd at al., 2012). The present results, however, are not in favor of the presence of any statistically significant differences in terms of birth weight between the respondents from the experimental and control groups, although critical birth weight was recorded for a few respondents from the experimental group, but their anamnesis led to the conclusion that they had no neurological defects during the early psychomotor development.

The absence of statistically significant difference in the birth weight between the respondents from the experimental and control groups complies with the findings of Reilly and associates (Reilly et al., 2009) and McAllister and Collier (McAllister \& Collier, 2014), but it is contrary to the results of other authors (Walhovd, Fjell, \& Brown, 2012; Boulet, Schieve, \& Boyle, 2011). So, according to the results of Boulet and associates (2011), the highest risk of stuttering concerns the children born with the lowest weight: a significant percentage of development disorders and health problems is related to the children born with weight of $<3000 \mathrm{~g}$, whereas the risk increases for children born with $<2500$ g compared to the children with normal birth weight (Boulet, Schieve, \& Boyle, 2011). Rygaard (1998, according to the Author, 2006) also warns that the birth weight (too low and too high) has the element of risk to the "early emotional frustration" phenomenon and, consequently, also causes difficulties in verbal functioning.

All these inferences certainly deserve a serious empirical verification within different research projects on larger samples of respondents. The same also applies to the results obtained in relation to the differences between the experimental and control groups on personality variables in this study.

In current empirical records, the most heated debates focus precisely on the differences in personality characteristics between adults who stutter and those

\section{from the typical population.}

Contrary to the authors, who claim there is no reliable evidence about the existence of differences in this domain (Bloodstein \& Bernstein-Ratner, 2008; Manning \& Beck, 2013), there are authors who prove that such differences exist (Iverach et. al., 2009, 2010; Jafari et al., 2014; Bleek, Montag, Faber, \& Reuter, 2011). Some authors even make efforts to find argumentation in favor of thesis that personality disorders, as well as other risks that affect mental health, are significantly more common in the case of stuttering people compared to those deprived of any speech dysfunctionality (Iverach et al., 2009).

Starting from the 'Big-Five' model, Jafari and associates (Jafari, Shahbodaghi, Ashayeri, Mohammadreza, \& Baziyar, 2014), compared the test results (scale of NEOFFI Inventory) obtained on a sample of 20 adults with disfluent speech from the experimental group, to the results obtained on a sample of the same size of adult respondents from the control group matched by gender and age. They found the presence of statistically significant differences on Neuroticism and Conscientiousness subscales between the two groups, where almost all scores on these dimensions were increased for adults with disfluent speech. 
The findings of Bleek and associates (Bleek at al., 2011, 2012) and of Iverach and associates (Iverach et al., 2010) are in favor of increased scores on Neuroticism dimension for adult respondents who stutter, contrary to the control ones. However, their findings are completely contradictory for aspects concerning the other two dimensions: Conscientiousness and Agreeableness, for which both studies find that, in addition to Neuroticism, significantly differentiate stuttering respondents from those from the control group. In fact, Iverach and associates (2010) prove that respondents from the experimental group achieve lower scores on Conscientiousness and Agreeableness subscales compared to normative sample, whereas Bleek and associates (2011) found through the tests of Conscientiousness and Agreeableness in a carefully selected control group (matched by gender, age and absence of stuttering) that scores for stuttering adults are significantly higher than those from the control group. We can therefore conclude that any research require careful selection, not only the experimental group, but also of the control one, in order to establish distinctive characteristics of stuttering people compared to respondents without this disorder (which was conducted in the present study). In another research, conducted on a sample of 112 stuttering people from Germany, Bleek and associates (2012) established that high Neuroticism and Introversion (low Extraversion) have an important indirect influence on stuttering in everyday life and possibly on the treatment. Iverach and associates (2009) report that stuttering increases the risk of personality disorder development (in particular: four to seven times in case of dissocial, anxious, borderline and paranoid personality disorders, i.e. two to three times in case of histrionic, impulsive and anankastic ones). Contrary to the results of all mentioned studies, those of the present one have shown that there are no statistically significant differences as to the basic personality domains between people treated in referent institution and adults from typical population. This finding is also consistent with the findings of other authors who prove that adults who stutter are neither more neurotic nor more maladjusted than adults without this disorder, as well as that there are no significant differences in personality traits among them (Bloodstein \& Bernstein-Ratner, 2008; Manning \& Beck, 2013).

Our results are also concordant with the view of authors who claim inconsistency of the records used in the attempt to show that stuttering individuals have specific set of personality traits; actually, there is overlapping between stuttering people and those without this disorder, concerning their personality traits, as well as their adaptation and emotional health (Bloodstein \& Bernstein-Ratner, 2008; Manning \& Beck, 2013).

Since this research found no differences between the experimental and control groups for Neuroticism dimension, whose important aspect is anxiety, and the subscale itself on the examined sample has a good reliability, it can be concluded that the respondents from our experimental group have no primary anxiety enhanced through basic neurotic structure, as is the case with the respondents from experimental samples of other authors (Iverach et al., 2010; Bleek et al., 2011). Analogously, possible symptoms of anxiety, depression and fear of negative evaluation for adults who stutter from our sample are secondary with respect to the stuttering as such and result from the awareness of difficulties in the communication. Therefore, if they appear, they are reactive in their nature and are not an indication of the enhanced personality trait (from neuroticism domain) compared to those who do not stutter.

As such, these symptoms are reduced with sufficient success by means of a speech therapy, especially if the mentioned method (SSR) is applied. It has been confirmed through practice and the application thereof allows to include both cognitive and behavioral correlates of stuttering (Dobrota, Otašević, \& Radević, 2018). 
Our research has generated no indications that the risk of psychopathological tendencies and personality disorders of adults who stutter is enhanced compared to the case of fluently speaking people, which is contrary to findings of Iverach and associates (2009) mentioned above, but concords with the results of Manning and Beck (Manning \& Beck, 2013) who established on a sample of 50 adult patients undergoing stuttering treatment, that only four patients fulfilled the criteria for one personality disorder, one patient for two personality disorders, whereas the other $90 \%$ of respondents did not fulfil the criteria for this diagnosis, i.e. the rates of personality disorders established in the examined sample are approximately equal to those found in the control samples of the general population. Comparing our data to those mentioned earlier indicates that the present results prove that the reports of other scientists in favor of high percentages of personality disorders for the adults who stutter (Iverach et al., 2009) are a consequence of a nonselective use of self-reports, wherein the existence of dysfunctionality within a personality and comorbidity with other disorders are overestimated. For instance, on a sample of 92 respondents, Iverach and associates (Iverach at al., 2009; 2010), found that even 64.1\% of them fulfilled the criteria for diagnosing at least one personality disorder, and even $43.44 \%$ of the respondents fulfilled the criteria for two or more personality disorders. The most frequent personality disorders were: anxiety (28.26\%), impulsiveness $(27.17 \%$, ) and paranoid disorder (26.09\%).

Finally, the present study found no statistically significant differences in the personality structure of men and women included in the stuttering treatment, justifying the practice of applying the same approach in rehabilitation of stuttering for both genders, thus facilitating specialists' work. Nevertheless, we could not generalize this finding as it ought to be tested in future investigation on larger samples with equal number of men and woman who stutter.

\section{CONCLUSION}

Based on the results obtained through the present study, several conclusions can be derived therefrom: 1. There are statistically significant differences in the frequency of male respondents who attend speech therapy because of stuttering compared to the frequency of women with the same diagnosis (male patients are twice as many); 2. The existence of a statistically significant difference concerning the birth weight between the respondents from the experimental and control groups is not established;

3. No statistically significant differences in basic personality dimensions between adults who stutter and the respondents from the control group are found; 4. No statistically significant differences are established in the personality structure between men and women attending speech treatments for stuttering. The obtained results may only serve as a starting point for understanding the issue and for conducting further empirical research on the characteristics of the adult people with speech fluency disorders. This is especially true for birth weight being a risk factor for stuttering. In this respect, we need more complex research project and detailed anamnestic data that would indicate that low birth weight is factor resulting in neurological deficits relevant to speech fluency.

According to the descriptive indicators for the nonexistence of statistically significant differences in the basic personality domains between the examined groups, speech therapy is attended by adult people who stutter, but who are, in their conative characteristics, comparable to persons from the typical population who do not stutter. They are not under risk that basic personality characteristics, acting as mediator, could make the rehabilitation-habilitation process more difficult, neither is necessary with regard to gender to make any differential approach to therapy. Therefore, treating the stuttering disorder in their case can be expected to have optimal effectiveness, especially the applied method (SSR) has proven itself in the existing practice of speech therapy as efficient, even for people with symptoms of psychopathological tendencies (Dobrota, Otašević, \& Radević, 2018). 
However, any more precise conclusion regarding the influence of gender, birth weight and basic personality dimensions on stuttering requires larger number of random chosen respondents and more sophisticated levels of data analysis. In this respect, it should be pointed out that the findings of the present study are limited by small and non-representative samples, and when it comes to personality domains, the findings are also limited by low reliability of the measuring instrument on subscale Openness (partly also Agreeableness), as well as the heterogeneity within the experimental group as to the stuttering degree and the time when a patient was subjected to the rehabilitation-habilitation treatment. Further examinations of the personality structure for adult people with speech fluency disorders are needed not only to achieve correct selection and prediction of treatment outcome, but because of the stereotypes that contribute to exaggerating the personality dysfunctionality for such people, as well. The lack of valid, scientifically reliable documents, maintains these stereotypes persistent even among speech specialists.

\section{REFERENCES}

Ambrose, N., Cox, N., \& Yairi, E. (1997). The genetic basis of persistence and recovery in stuttering. Journal of Speech, Language and Hearing Research, 40(3), 567-580.

Bleek, B., Montag, C., Faber, J., \& Reuter, M. (2011). Investigating personality in stuttering: Results of a case control study using the NEO-FFI. Journal of Communication Disorders, 44(2), 218-222.

Bleek, B., Reuter, M., Yaruss, S., Cook, S., Faber, J., \& Montag, C. (2012). Relationships between personality characteristics of people who stutter and the impact of stuttering on everyday life. Journal of Fluency Disorders, 37(4), 325-333.

Bloodstein, O., \& Bernstein-Ratner, N.(2008). A Handbook on Stuttering. Delmar Learning, 6th ed.Clifton Park, NY. Delmar Learning.

Boulet, S., Schieve, L., \& Boyle, C. (2011). Birth weight and health developmental outcomes in US children. Maternal and Child Health Journal, 15(7), 836-844.

Cykowski, M.D., Fox, P.T., Ingham, R.J., Ingham, J.C., \& Robin, D.A. (2010). A study of the reproducibility and etiology of diffusion anisotropy differences in developmental stuttering: a potential role for impaired myelination. NeuroImage, 52(4), 1495-1504.

Costa, P. T., Jr., \& McCrae, R. R. (1992). Revised NEO Personality Inventory (NEO-PI-R) and NEO Five-Factor Inventory (NEO-FFI) professional manual. Odessa, FL: Psychological Assessment Resources.

Cox, N., Roe, C., Suresh, R., Cook, E., Lundstrom, C., Garsten, M., Ezrati, R. Ambrose, N., \& Yairi, E. (2005). Chromosomal signals for genes underlying stuttering. Oxford Disfluency Conference. Oxford University, Oxford, UK.
Dobrota, N., Otašević, J., \& Radević Lj. (2018). The impact of Stuttering on acquiring Academic knowledge in Children of school age. Human: Journal for Interdisciplinary Studies, 8(2), 71-78.

Digman, J.M. (1990). Personality structure: Emergence of Five Factor Model. Annual Review of Psychology, 41, 417-440.

Iverach, L., Jones, M., O’Brian, S., Block, S., Lincoln, M., Harrison, E., Hewat, S., Cream, A., Menzies, R., Packman, A., \& Onslow. M. (2009). Screening for personality disorders among adults seeking speech treatment for stuttering. Journal of Fluency Disorders, 34(3), 173-186.

Iverach, L., O’Brian, S., Jones, M., Block. S., Lincoln, M., Harrison, E., Hewat, S., Menzies, R. G., Packman, A., \& Onslow, M. (2010). The five factor model of personality applied to adults who stutter. Journal of Communication Disorders, 43, 120-132.

Jafari, R., Shahbodaghi, R., Ashayer, H., Mohammadreza K., \& Baziyar, M. (2014). The Five Factor Model of Personality and Stuttering. Procedia - Social and Behavioral Sciences, 127, 307-310.

Knežević, G., Radović, B., \& Opačić, G. (1997). Evaluation of the "Big Five" personality model through the analysis of the personality inventory NEO PI-R. Psychology, 1-2, 7-40. (in Serbian).

Knežević, G., Jocić-Đurić, D., \& Džamonja-Ignjatović, T. (2009). NEO PI-R: Application an interpretation. Centre for Applied Psychology, Belgrade. (in Serbian).

Manning, W., \& Beck, J.G. (2013). Personality dysfunction in adults who stutter. Journal of Fluency Disorders, 38 (2), 184-192.

McAllister, J., \& Collier, J. (2014). Birth weight and stuttering: Evidence from three birthcohorts. Journal of Fluency Disorders, $39,25-33$.

Packman, A. (2012). Theory and therapy in stuttering: A complex relationship. Journal of Fluency Disorders, 37(4), 225-233.

Radoman, V. (2004). The development of theoretical models of disability and language disability. Research in defectology, 5, 33-48. (in Serbian).

Radulović, D. (2006). Psychology of crime psychopathy and crime. Institute for Criminological and Sociological Research. Faculty of Special Education and Rehabilitation, Belgrade. (in Serbian).

Reilly, S., Onslow, M., Packman, A., Wake, M., Bavin, E.L., Prior, M., Eadie, P., Cini, E., Bolzonello, C., \& Ukoumunne, O.C. (2009). Predicting stuttering onset by the age of 3 years: A prospective, community cohort study. Pediatrics, 123(1), 270-277.

Tran, Y., Blumgart, E., \& Craig, A. (2011). Subjective distress associated with chronic stuttering, Journal of Fluency Disorders, 36(1), 17-26.

Watkins, R., Yairi, E., \& Ambrose, N.G. (1999). Early childhood stuttering III: Initial status of expressive language Abilities. Journal of speech, Language and hearing Research, 42(5), 1125-1135.

Walhovd, K.B., Fjell, A.M., Brown, T.T., Kuperman, J.M., Chung, J., Hagler, D.J.,... \& Dale, M.A. (2012). Long-term influence of normal variation in neonatal characteristics on human brain development. Proceedings of the National Academy of Science of the USA, 109(49) 20089-20094.

Yairi, E. \& Ambrose, N. (2013). Epidemiology of stuttering: 21st Century advances. Journal of Fluency Disorders, 38(2), 66-87. 